\title{
Sri Lanka: An Amphibian Hot Spot
}

\section{Meegaskumbura, ${ }^{1,2}$ F. Bossuyt, ${ }^{3,4}$ R. Pethiyagoda, ${ }^{2}$ K. Manamendra-Arachchi, ${ }^{2}$ M. Bahir, ${ }^{2}$ M. C. Milinkovitch, ${ }^{4}$ C. J. Schneider ${ }^{1 *}$}

Dramatic population declines have affected frogs worldwide (1), and, although new species continue to be described (2), the discovery of large new species radiations is rare. Here, we report the discovery of an endemic radiation of $>100$ species of Old World tree frogs (Rhacophorinae) from Sri Lanka, an island from which only 18 rhacophorine species were known previously (3). An extensive survey, primarily in the island's remaining $750 \mathrm{~km}^{2}$ of rain forest, revealed upwards of 140 anuran species, making Sri Lanka an amphibian hot spot of global importance (4).

The new species were diagnosed by differences in morphology, ecology, bioacoustics, and/or genetics (5), and their novelty was established through comparison with all available Sri Lankan amphibian type material in museums worldwide. Phylogenetic analyses (5) of mitochondrial DNA sequences from $32 \mathrm{Sri}$ Lankan species and representatives of all genera of Asian rhacophorines revealed that the Sri Lankan species belong to two distinct monophyletic groups (Fig. 1). One clade contains species of Polypedates that lay their eggs in foam nests. The second contains all remaining species, whose eggs undergo terrestrial direct development (Fig. 1, A and B) and whose ecological and morphological diversity is reflected by the placement of previously described species in three separate genera (Fig. 1C). The latter group, the vast majority of whose members are previously unknown to science, forms a strongly supported clade whose sister group is represented by two species of direct-developing rhacophorine frogs (6)

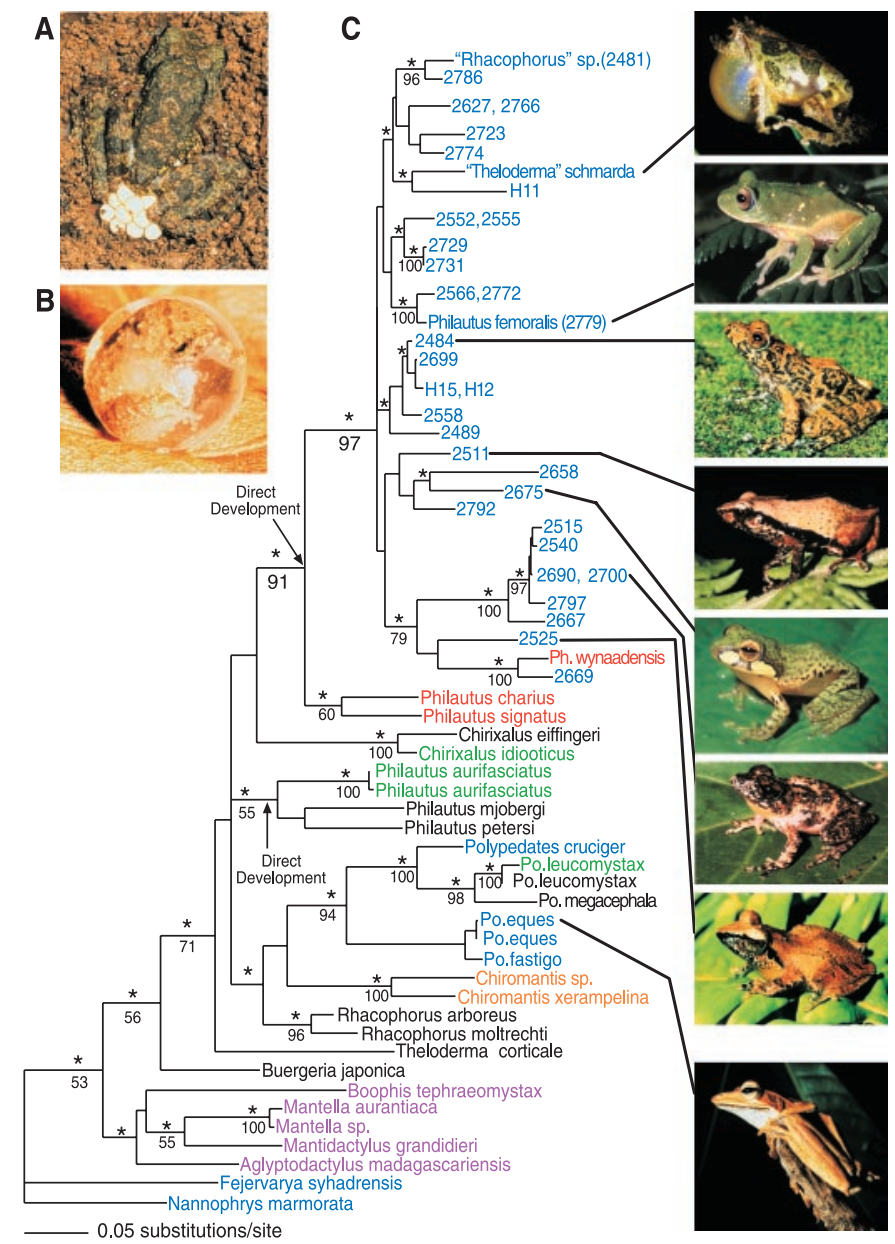

Fig. 1. (A) Mating pair of species $\mathrm{H} 11$ laying terrestrial, direct-developing eggs. (B) Froglet inside egg before hatching. (C) Maximum likelihood tree from 802 base pairs of mitochondrial 12S and 16S rRNA genes from Sri Lankan (blue), Indian (red), Javan (green), Asian (black), Madagascan (violet), and African (orange) taxa (5). Asterisks above branches indicate posterior probabilities $>95 \%$; values below branches indicate equal-weights parsimony bootstrap support. Numerical designations of OTUs are Wildlife Heritage Trust of Sri Lanka collection numbers (solely numerical designations indicate undescribed species). Direct development is depicted as having evolved independently in Philautus and the Sri Lankan/Indian clade, but it may have evolved only once if Philautus and the Sri Lankan/Indian radiation form a clade $(5,8)$. from the Western Ghats of southern India.

Sri Lanka, together with the Western Ghats, is one of the world's biodiversity hot spots, and the magnitude of its amphibian fauna had been considered well known (7). Our discovery that the anuran fauna is many times richer than previously estimated is therefore unexpected. However, many species known from 19th-century museum collections were not recorded in our survey and are probably extinct. Given that the island has lost more than $95 \%$ of its rain forest habitat, this is hardly unexpected. Still, the persistence of so many species is striking and may be attributable to a combination of terrestrial eggs, direct-developing embryos, and high fecundity (up to 91 ova per clutch).

Sri Lanka's amphibian diversity (about 140 species on an island of $65,610 \mathrm{~km}^{2}$ ) now approaches or exceeds that of many amphibian diversity hot spots and is comparable to those of tropical islands an order of magnitude larger, such as Borneo $\left(746,300 \mathrm{~km}^{2}\right.$; 137 species $)$, Madagascar $\left(587,000 \mathrm{~km}^{2} ; 190\right.$ species), New Guinea $\left(775,200 \mathrm{~km}^{2} ; 225\right.$ species), and the Philippines $\left(299,800 \mathrm{~km}^{2}\right.$; 96 species). Measures to preserve Sri Lanka's amphibian diversity should include preservation of remaining forest fragments as well as habitat restoration. The discovery of a new anuran radiation in Sri Lanka suggests that other rich vertebrate faunas may await discovery elsewhere in tropical Asia.

\section{References and Notes}

1. J. M. Kiesecker, A. R. Blaustein, L. K. Belden, Nature 410, 681 (2001).

2. F. Glaw, J. Köhler, Herp. Rev. 29, 11 (1998).

3. S. K. Dutta, K. Manamendra-Arachchi, The Amphibian Fauna of Sri Lanka (Wildlife Heritage Trust of Sri Lanka, Colombo, Sri Lanka, 1996).

4. R. Pethiyagoda, K. Manamendra-Arachchi, Occ. Pap. Wildl. Heritage Trust Sri Lanka 2, 1 (1998).

5. Methods and materials and data set are available as supporting online material.

6. F. Bossuyt, M. C. Milinkovitch, Proc. Natl. Acad. Sci. U.S.A. 97, 6585 (2000).

7. R. F. Inger, in Patterns of Distribution of Amphibians, W. E. Duellman, Ed. (Johns Hopkins Univ., Baltimore, MD, 1999), pp. 445-482.

8. F. Bossuyt, A. Dubois, Zeylanica 6, 1 (2001).

9. Supported by Boston University, the NSF (DEB 9977072), the Wildlife Heritage Trust of Sri Lanka, the Fund for Scientific Research (FWO) Flanders, the National Fund for Scientific Research Belgium (FNRS), and the "Communauté Française de Belgique" (ARC 98/03223). Research permission from the Department of Wildlife Conservation Sri Lanka and tissue loans from the Raffles Museum of Biodiversity Research (Singapore) are gratefully acknowledged.

\section{Supporting Online Material}

www.sciencemag.org/cgi/content/full/298/5592/379/ DC1

${ }^{1}$ Biology Department, Boston University, Boston, MA 02215, USA. 'Wildlife Heritage Trust, 95 Cotta Road, Colombo 8, Sri Lanka. ${ }^{3}$ Free University of Brussels ( VUB), Biology Department, Unit of Ecology and Systematics, Pleinlaan 2, B-1050 Brussels, Belgium. ${ }^{4}$ Unit of Evolutionary Genetics, C.P. 300, Institute of Molecular Biology and Medicine, Rue Jeener \& Brachet 12, B-6041 Gosselies, Belgium.

*To whom correspondence should be addressed. Email: cschneid@bu.edu 